\title{
Application of Small Angle X-ray Scattering (SAXS) for Differentiation between Normal and Cancerous Breast Tissue
}

\author{
Vahid Changizi ${ }^{1}$, Mohammad A. Oghabian ${ }^{1}$, Robert Speller ${ }^{2}$, Saeed Sarkar ${ }^{1}$, Ali Arab Kheradmand ${ }^{1}$ \\ 1. Department of Medical Physics, Faculty of Medicine, Tehran University of Medical Sciences, \& Research Center for Science \& \\ Technology in Medicine, Imam Khomaini Hospital, Bolvare Keshavarz, Tehran, Iran \\ 2. Department of Medical Physics and Bioengineering, University College London, Gower Street, London WC1E 6BT, UK
}

Corresponding address: Vahid Changizi. changizi@sina.tums.ac.ir

Received: 2005.02.07; Accepted: 2005.06.20; Published: 2005.07.05

Introduction: Small angle, between $3^{\circ}$ and $10^{\circ}, \mathrm{X}$ ray scattering is predominantly coherent giving rise to diffraction effects that can be observed as constructive and destructive interferences. These interferences carry information about the molecular structure of the tissue and hence can be used to identify changes that occur due to cancer.

Method: In this study an energy dispersive X-ray diffraction method was used. The optimum scattering angle, determined from a series of measurements on adipose breast tissue at several angles from 4 to 7.3 degrees, was found to be $6.5^{\circ}$. Once optimized the system was used to measure the diffraction profiles (corrected scattered intensity versus momentum transfer) of a total of 99 breast tissue samples. The samples were both normal and tumour samples.

Results: Adipose tissue showed a sharp, high intensity peak at low momentum transfer values of approximately $1.1 \mathrm{~nm}-$ 1. Adipose tissue, mixed tissue (adipose \& fibroglandular) and tumor have peaks at different values of momentum transfer that can be used to identify the tissue. Benign and malignant breast tissues can also be differentiated by both peak positions and peak heights. It was also observed that the results were reproducible even after the tissue had been preserved at liquid nitrogen temperatures.

Conclusion: We were able to differentiate between normal, benign and malignant breast tissues by using energy dispersive small angle x-ray scattering.

K eywords: small angle $\mathrm{x}$-ray scattering, normal and cancerous breast tissues

\section{Introduction}

Breast cancer is the most widespread cancer in women. Incidence rates are continuously increasing in many parts of the world and currently, in the industrial world, the rate is about one in 12 . It is a major cause of death in middle-aged women of 33-55 years [11] and the need for early and more accurate diagnosis has been identified as a major factor that could help in saving many womens lives.

Scattering of X-rays at small angles is dominated by coherent (elastic) scattering. These coherent scattering events interfere and produce diffraction effects. The latter gives rise to a unique scattering signature characteristic of the tissue that has been irradiated. This signature is dependant upon the molecular composition of the target and hence could be used to characterize the tissue. There have been several papers describing possible applications of these effects. Kosanetzky et al [6] presented the diffraction patterns for some plastics and several biological samples. The characteristic nature of scattering was also reported by Evans et al [2]. More recently the sensitivity of photon scattering due to molecular level changes in tissue was presented by Kidane et al [5]. By using SAXS, systematic differences in the intensities and d-spacing have been clearly demonstrated among the collagen of normal, malignant and benign breast tissues by Lewis et al [7]. Furthermore, Keyrilainen et al showed that the average intensity of scattering from cancerous regions is an order of magnitude higher than the intensity from healthy regions [3]. As a clear demonstration of how the scattering profile is material dependant, Poletti et al demonstrated that tissue equivalence for X-ray transmission does not lead to tissue equivalence in scattering properties [12].

Applications outside of the biomedical field have also been reported. Malden et al [8] used CdZnTe detectors to collect energy dispersive diffraction spectra at a range of scattering angles, obtained from sheets of explosive materials hidden in baggage. They have shown that the combined information from these 'signatures' can be used to determine whether an explosive sample is present or not. In another example, Desouky et al, presented low angle X-ray scattering profiles for five different spices; anise, coriander, cumin, fennel and nigella [1].

It is clear that there exists a body of data on tissue scattering. However, in order to evaluate possible applications of small angle $x$-ray scattering as a diagnostic tool, it is important that its ability to distinguish normal from benign disease and benign from malignant breast disease be established. This paper looks at the scattering profiles obtained from normal, benign and malignant breast tissues.

\section{Materials and methods}

Equipment - Energy Dispersive X- Ray Diffraction (EDXRD) was used. A schematic diagram of the small angle $x$-ray scattering set up is shown in Figure 1.

The tungsten target X-ray tube was operated at 10 $\mathrm{mA}$ and $60 \mathrm{kV}$. Two collimators, acceptance angle approximately $1^{\circ}$, were used to define the incident and scattered beams of $1 \mathrm{~mm}$ diameter. The source to sample distance was $150 \mathrm{~mm}$ and sample to detector distance was 
$170 \mathrm{~mm}$. All system components were mounted on an isolated optical table.

The detection system was a planar HpGe detector (model GEM, Ortec EG\&G) with energy resolution of 850 $\mathrm{eV}$ at $59.7 \mathrm{keV}$. In order to minimize multiply scattered background from the laboratory, lead was placed around the detector. The output pulses were fed to a PC - based multichannel analyzer (92X Spectrum Master, EG\&G Ortec). The analyzer was used to digitize the analog information contained in each pulse, to process and store the data in memory and finally to display the contents of the processed data in the form of counts against channel number. Channel number was converted into photon energy by performing a calibration using Am-241.

All samples were prepared as $5 \mathrm{~mm}$ diameter and 5 $\mathrm{mm}$ height pieces of tissue contained in low scattering, thin walled plastic holders. In order to obtain scatter signatures the samples were positioned at the center of the scattering volume defined by the collimation geometry. During the scatter measurements, the sample was rotated at constant speed to ensure that all parts of the tissue sample were exposed uniformly to the beam.

The total counting time per sample was 500 seconds giving rise to a statistical error of 0.02 per channel.

Raw data corrections - Raw scatter data were corrected as follows:

- Energy values were transformed into momentum transfer values by using $Q=(1 / \lambda) \sin (\theta / 2)$ where $\lambda$ is the wavelength of the radiation used and $\theta$ the scatter angle.

- The background due to scattering from the sample holder was subtracted from the raw data.

- Each measured spectrum was corrected for the shape of the incident spectrum. This allows comparison with other worker's data.

- Finally, baseline subtraction was performed for each coherent intensity versus momentum transfer curve.

Evaluation of optimum scattering angle - In order to obtain the optimum scattering angle, the diffraction profiles of a test adipose sample were measured over a range of scattering angles from $4^{\circ}$ to $7.3^{\circ}$. The optimum, in terms of peak width and peak intensity was found to be at an angle of $6.5^{\circ}$. Therefore, all other tissue sample measurements were performed at $6.5^{\circ}$ and at a temperature of $18^{\circ} \mathrm{C} \pm 1^{\circ} \mathrm{C}$.

Samples - A total of 99 samples were collected from women who underwent mastectomy at the Imam Khomaini hospital, Tehran, Iran. A section from each sample was sent for histological analysis whilst the remaining tissue was prepared for scatter analysis. All measurements were made with the tissue at room temperature and all tissues were stored between measurements at liquid nitrogen temperature. Histological analysis of the samples gave the following breakdown of tissue types: 20 pure adipose tissues, 17 mixed (adipose plus fibroglandular) normal tissues, 41 carcinoma and 21 fibrocystic changes.

Effects of storage - In order to study the effects of tissue storage upon the diffraction profiles measurements were made within 1.5 hours of harvesting and then repeated at intervals of two months during which the tissue was stored at liquid nitrogen temperatures.

\section{Results}

Mean diffraction profiles for the four different tissue types studied in this work are shown in Figure 2. Adipose tissue presents a sharper peak at lower momentum transfer values compared with other tissues. The width of the curve for tumors is noticeably greater than for adipose tissue. Table 1 gives mean values for the peak positions and widths. It can be seen that the peak height $(0.11 \pm 0.01$ normalized relative intensity) for adipose is more than for tumors $(0.09 \pm 0.01$ for carcinoma and $0.07 \pm 0.02$ for fibrocystic change) as well as for fibroglandular $(0.08 \pm$ 0.01).

Table 2 tabulates the significance, obtained by student's t-test, of the change of peak position between different tissues. It can be seen that peak position, is a reliable way to differentiate between normal and tumor breast tissues. Furthermore, it is possible to differentiate between fibrocystic changes and carcinoma using this parameter. The difference between adipose and tumors is further highlighted and even though the fibroglandular and fibrocystic changes peaks are close, they are statistically separated.

Using the results in Table 2 effective d-spacings have been found. These are 0.33, 0.36, 0.46 and $0.4 \mathrm{~nm}$ for carcinoma, fibrocystic changes, adipose and fibroglandular tissues respectively.

Comparison of the measured signatures between the fresh and frozen tissues is shown in Figure 3. It can be seen that there are no significant differences between the fresh and frozen samples in terms of their diffraction profiles.

\section{Discussion}

A noticeably shaper peak in the diffraction profile was obtained for adipose compared to other tissues. This is a result of the high levels of lipid fat cells that exist in adipose tissue.

Figure 2 shows that in this study peak positions can be used to identify tissues and their positions in this study are similar to the results obtained by Kidane et al (1999). The peak positions for the adipose and carcinoma were $1.09 \pm 0.03 \mathrm{~nm}-1$ and $1.53 \pm 0.03 \mathrm{~nm}-1$ respectively. Connective tissue that supports the malignant cells varies in composition from fibroblastic to densely hyaline and contains varying amounts of collagen, extra cellular mucin and elastic tissue [9]. This tissue replaces fat as the tumour invades it. Thus, carcinoma is typically characterized by the lack of isolated pockets of fat within its mass and this is demonstrated in these results by the lack of any adipose peak in the carcinoma diffraction profile.

The peak positions for the adipose and fibrocystic changes were $1.09 \pm 0.03 \mathrm{~nm}-1$ and $1.38 \pm 0.04 \mathrm{~nm}-1$ respectively. In this case, adipose tissue has been replaced by fibrocystic changes. Fibrocystic changes as lobular lesions in which the individual acini or terminal ductules dilate, untwist, and unfold to produce a solitary locule that then enlarges as a cyst. Understandably, fibrosis is often reported by pathologists in an attempt to explain clinical palpability or mammographic density [4]. But adenocarcinoma including ductal carcinoma, lobular carcinoma and in-situ ductal carcinoma studied in this work is referred to as glandular tissue. Therefore, it is expected different peak positions will exist for carcinoma and fibrocystic changes. Our results confirmed this expectation. The peak position of fibrocystic change was close to that of carcinoma. However, the t-test examination revealed that they could be separated statistically into two different groups. In all cases p-value were less than 0.0001 . 
It was found that the total integrated intensity of coherent scattering from cancerous tissues is higher than that of normal adipose tissue. This is similar to the finding of Keyrilainen et al [3], although the diffraction profiles differ. This is possibly due to the angular dispersive technique used by Keyrilainen et al.

\section{Conclusion}

Measurements of coherently scattered X-ray photons can be used to identify breast disease. In this study using diffraction profiles from EDXRD, distinct peak positions were obtained for different breast tissues including adipose $(1.09 \pm 0.03 \mathrm{~nm}-1)$, fibroglandular $(1.25 \pm 0.05 \mathrm{~nm}-1)$, carcinoma $(1.53 \pm 0.03 \mathrm{~nm}-1)$ and fibrocystic tissues $(1.38 \pm 0.04 \mathrm{~nm}-1)$. It has been shown that these differences are significant $(p<0.001)$ and therefore allow tissues to be characterized. It was also shown that peak height (i.e., scattered intensity) could help differentiate between normal tissue and breast tumours. As the result, this method could be adapted for use in mammography for the early detection of breast cancer.

There were no significant differences in peak position, peak height or area between diffraction curves obtained from tissue before and after storing at liquid nitrogen temperatures. Therefore, it can be concluded that freezing does not create any molecular changes that can be observed in these measurements.

\section{Acknowledgments}

This study has been supported by the Tehran University of Medical Sciences. We would like to thank The Institute of Applied Physics for its collaboration.

\section{Conflict of interest}

None declared.

\section{References}

1. Desouky OS, Ashour AH, Abdullah MI, Elshemey WM. Low angle X-ray scattering from spices. Radiation Physics and Chemistry 2002; 64: 267-271.

2. Evans SH, Bradley DA, Dance DR, Bateman JE, Jones CH. Measurement of small angle photon scattering for some breast tissues and tissue substitute materials. Phys Med Biol 1991; 36 (1): 718.

3. Fernandez M, Keyrilainen J, Serimaa R, Torkkeli M, KarjalainenLindsberg ML, Tenhunen M, Thomilnson W, Urban V, Suortti P. Small angle $\mathrm{x}$-ray scattering studies of human breast tissue samples. Phys Med Biol 2002; 47: 577-592.

4. Harris JR, Lippman ME, Morrow M, Osborne C. Diseases of the breast (second edition). Philadelphia: Lippincott Williams and Wilkins. 1999.

5. Kidane G, Speller RD, Royle GJ, Hanby AM. X-ray scatter signatures for normal and neoplastic breast tissues. Phys Med Biol 1999; 44: 1791-1802.
6. Kosanetzky J, Knoerr B, Harding G, Neitzel U, et al. X-ray diffraction measurement of some plastic materials and body tissues. Med Phys 1987; 14 (4): 1811-1816.

7. Lewis RA, Rogers KD, Hall CJ, Towns-Andrews E, Slawson S, Evan A, Pinder SE, Ellis IO, Boggis CRM, Hufton AP and Dance DR. Breast cancer diagnosis using scattered X-rays. J Synchrotron Rad 2000; 7: 348-352.

8. Malden $\mathrm{CH}$, Speller RD, et al. A CdZnTe array for the detection of explosives in baggage by energy dispersive X-ray diffraction signatures at multiple scatter angles. Nuclear Instruments and Methods in Physics Research A. 2000; 449: 408-415.

9. Mills RR, Hanby AM, Girling AC. Diagnostic Surgical Pathology. New York: Raven. 1994.

10. Morin LRM. Molecular form factors and photon coherent scattering cross sections of water. J Phys Chem 1982; 11: 1091.

11. Parking DM, Laara E, Muri CS, et al. Estimates of the world wide frequency of sixteen major cancers in 1980. Int J Cancer 1988; 41: 184.

12. Poletti ME, Goncalves OD, Mazzaro I. Measurements of X-ray scatter signatures for some tissue-equivalent materials. Nuclear Instruments and Methods in Physics Research B. 2004; 213: 595-598.

\section{Tables and Figures}

Table 1. Major parameters from the diffraction profiles measured at a scattering angle of $6.5^{\circ}$ for 99 breast tissue samples. The samples were histologically classified.

\begin{tabular}{|c|c|c|c|c|}
\hline $\begin{array}{c}\text { Tissue type } \\
\text { (histological } \\
\text { classification) }\end{array}$ & $\begin{array}{c}\text { Number } \\
\text { of } \\
\text { samples }\end{array}$ & $\begin{array}{c}\text { Peak } \\
\text { position } \\
\text { (nm }\end{array}$ & $\begin{array}{c}\text { FWHM } \\
\text { (nm }\end{array}$ & $\begin{array}{c}\text { Peak Height } \\
\text { (Normalized } \\
\text { relative } \\
\text { intensity) }\end{array}$ \\
\hline Carcinoma & 41 & $1.53 \pm 0.03$ & $0.3 \pm 0.05$ & $0.09 \pm 0.01$ \\
\hline Fibrocystic changes & 21 & $1.38 \pm 0.04$ & $0.29 \pm 0.03$ & $0.07 \pm 0.02$ \\
\hline Adipose & 20 & $1.09 \pm 0.03$ & $1.56 \pm 0.03$ & $0.125 \pm 0.015$ \\
\hline $\begin{array}{c}\text { Mixed (adipose+ } \\
\text { Fibroglandular) }\end{array}$ & 17 & $\begin{array}{c}1.09 \pm 0.03 \\
\& \\
1.25 \pm 0.05\end{array}$ & $\begin{array}{c}0.025 \pm \\
0.02\end{array}$ & $\begin{array}{c}0.12 \pm 0.01 \\
\& \\
0.08 \pm 0.01\end{array}$ \\
\hline
\end{tabular}

Table 2. Significance values for the student's t-test carried out on the peak positions associated with different types of breast disease.

\begin{tabular}{|c|c|c|c|c|c|c|}
\hline \multirow[t]{2}{*}{ Tissue type } & \multirow[t]{2}{*}{ Numbers } & \multirow[t]{2}{*}{$\begin{array}{c}\text { Peak } \\
\text { position } \\
\left(\mathrm{nm}^{-1}\right)\end{array}$} & \multirow[t]{2}{*}{$\begin{array}{c}\mathrm{T} \\
\text { value }\end{array}$} & \multirow[t]{2}{*}{$\begin{array}{r}\text { P- } \\
\text { value }\end{array}$} & \multicolumn{2}{|c|}{$\begin{array}{l}95 \% \text { confidence } \\
\text { interval of the } \\
\text { difference }\end{array}$} \\
\hline & & & & & lower & upper \\
\hline Carcinoma & 41 & $1.53 \pm 0.03$ & 13 & $\mathrm{P}<0.0001$ & 0.13 & 0.18 \\
\hline $\begin{array}{c}\text { Fibrocystic } \\
\text { changes }\end{array}$ & 21 & $1.38 \pm 0.04$ & & & & \\
\hline Carcinoma & 41 & $1.53 \pm 0.03$ & 65 & $\mathrm{P}<0.0001$ & 0.43 & 0.46 \\
\hline Adipose & 20 & $1.09 \pm 0.03$ & & & & \\
\hline $\begin{array}{c}\text { Fibrocystic } \\
\text { changes }\end{array}$ & 21 & $1.38 \pm 0.04$ & 25 & $\mathrm{P}<0.0001$ & 0.27 & 0.32 \\
\hline Adipose & 20 & $1.09 \pm 0.03$ & & & & \\
\hline Carcinoma & 41 & $1.53 \pm 0.03$ & 47 & $\mathrm{P}<0.0001$ & 0.27 & 0.3 \\
\hline Fibroglandular & 17 & $1.25 \pm 0.05$ & & & & \\
\hline $\begin{array}{c}\text { Fibrocystic } \\
\text { changes }\end{array}$ & 21 & $1.38 \pm 0.04$ & 12 & $\mathrm{P}<0.0001$ & 0.11 & 0.16 \\
\hline Fibroglandular & 17 & $1.25 \pm 0.05$ & & & & \\
\hline
\end{tabular}


Figure 1. Schematic experimental set up for EDXRD method with Hp Ge detector.

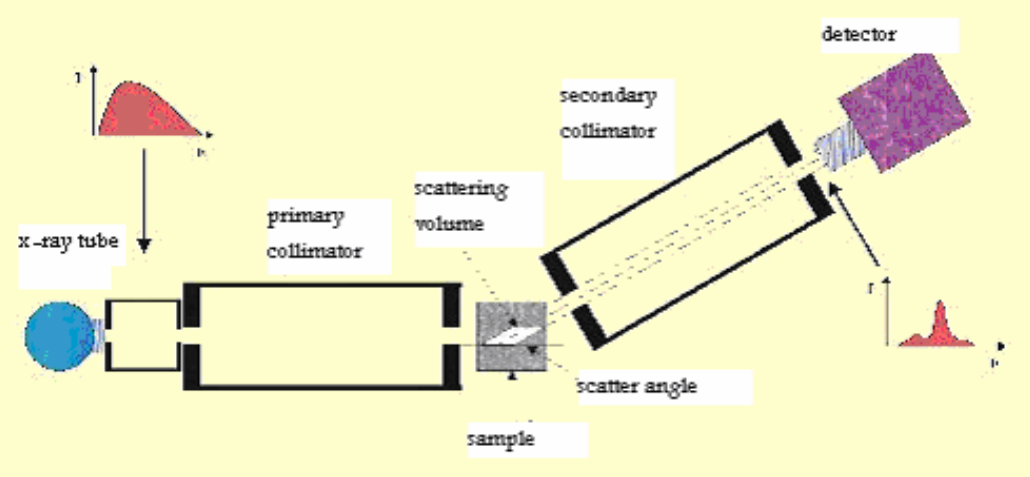

Figure 2: Mean corrected diffraction profiles for the tissue types listed in table 1. Each of the curves is the average value of corrected intensity of samples within its classification. The number of samples of each type is given in table 1 .

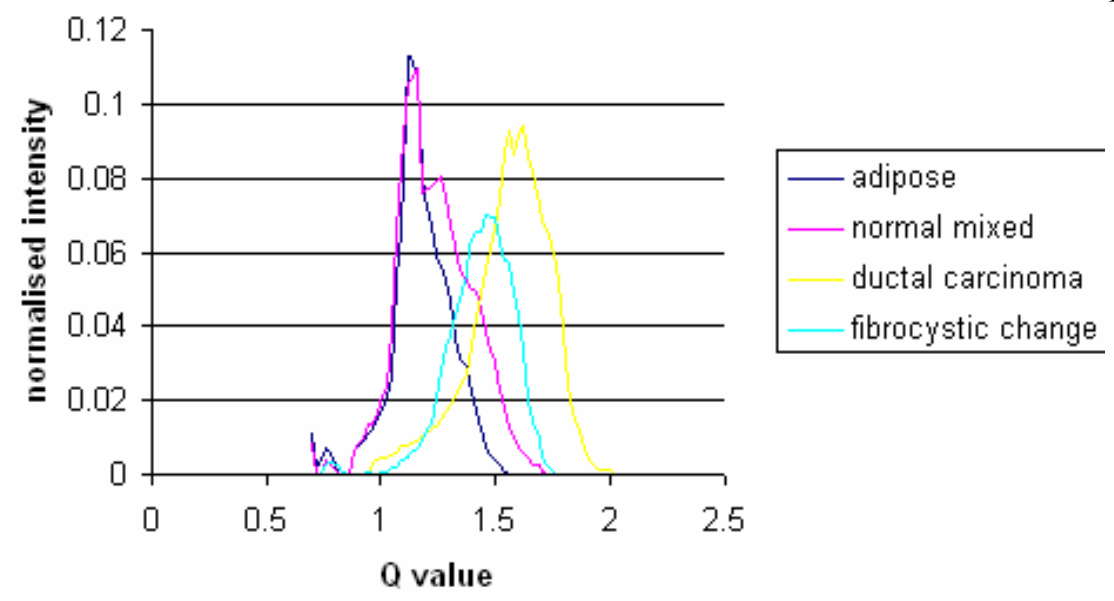

Figure 3: The corrected diffraction profile from adipose tissue before and after preserving in a liquid nitrogen facility for 2 months.

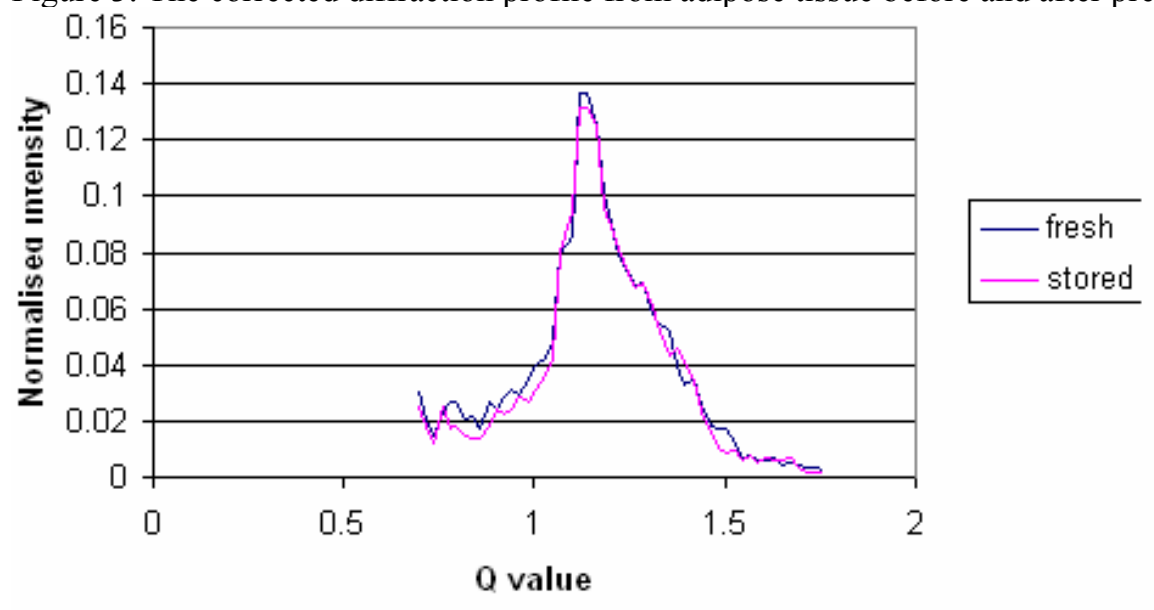

